Published in final edited form as:

Nat Immunol. 2013 December ; 14(12): 1256-1265. doi:10.1038/ni.2746.

\title{
HIV-1 gp120 impairs B cell proliferation by inducing TGF- $\beta 1$ production and FcRL4 expression
}

\author{
Katija Jelicic ${ }^{1}$, Raffaello Cimbro ${ }^{1,5}$, Fatima Nawaz ${ }^{1,4}$, Da Wei Huang ${ }^{2}$, Xin Zheng ${ }^{2}$, Jun \\ Yang $^{2}$, Richard A. Lempicki ${ }^{2}$, Massimiliano Pascuccio ${ }^{1}$, Donald Van Ryk ${ }^{1}$, Catherine \\ Schwing ${ }^{1}$, Joseph Hiatt ${ }^{1}$, Noreen Okwara ${ }^{1}$, Danlan Wei ${ }^{1}$, Gregg Roby ${ }^{1}$, Antonio David ${ }^{3}$, \\ Young Hwang $\mathrm{II}^{1}$, John H. Kehrl ${ }^{1}$, James Arthos ${ }^{1}$, Claudia Cicala ${ }^{1,{ }^{*}}$, and Anthony S. Fauci ${ }^{1},{ }^{*}$ \\ ${ }^{1}$ Laboratory of Immunoregulation, National Institute of Allergy and Infectious Diseases, National \\ Institutes of Health, Bethesda, Maryland 20892, USA \\ ²Laboratory of Immunopathogenesis and Bioinformatics, SAIC Frederick 21702, USA \\ ${ }^{3}$ Department of Internal Medicine, Faculty of Medicine, University of Messina, Messina Italy \\ ${ }^{4}$ New York University School of Medicine Sackler Institute of Graduate Biomedical Sciences New \\ York, NY 10016, USA \\ ${ }^{5}$ Department of Medicine, Johns Hopkins University School of Medicine, Baltimore, Maryland \\ 21224, USA
}

\begin{abstract}
The humoral immune response following acute HIV-1 infection is delayed and ineffective. The HIV-1 envelope protein gp120 binds to and signals through $\alpha_{4} \beta_{7}$ on T cells. We show that gp120 also binds and signals through $\alpha_{4} \beta_{7}$ on naïve $B$ cells, resulting in an abortive proliferative response. In primary B cells gp120 signaling through $\alpha_{4} \beta_{7}$ resulted in increased expression of the immunosuppressive cytokine TGF- $\beta 1$ and the B cell inhibitory receptor FcRL4. Co-culture of B cells with HIV-1-infected autologous CD4 ${ }^{+} \mathrm{T}$ cells also increased B cell FcRL4 expression. These findings indicate that, in addition to mediating chronic immune activation, viral proteins can
\end{abstract}

Users may view, print, copy, download and text and data- mine the content in such documents, for the purposes of academic research, subject always to the full Conditions of use: http://www.nature.com/authors/editorial_policies/license.html\#terms

Correspondence should be addressed to: Claudia Cicala (ccicala@niaid.nih.gov).

These two senior authors contributed equally to this work

Accession codes

GSE49019

Author Contributions

K.J. carried out the majority of the experiments, analyzed the results, participated in manuscript preparation; R.C. contributed to flow cytometric analysis and participated in manuscript preparation; F.N. carried out biological experiments including gp120 binding; D.W.H. carried out bioinformatics analyses and contributed to the interpretation of microarray data; X.Z. carried out oligonucleotide microarray analysis and bioinformatics analyses; J.Y. carried out quantitative PCR experiment; R.A.L. carried out bioinformatics analyses; M.P., D.V.R., C.S., produced and analyzed recombinant gp120. J.H., N.O., carried out biological experiments; D.W. carried out experiments including ELISA assay; G.R. recruited blood donors; A.D. provided technical and intellectual contributions; I.Y.H. carried out experiments and provided technical contributions for CFSE experiments; J.H.K. contributed to the analysis and to write the manuscript; J.A. contributed to study design and analysis and writing of the manuscript; C.C. conceived, designed, interpreted data, supervised the study and composed the manuscript; A.S.F. supervised the study and contributed to writing the manuscript; and all authors reviewed the manuscript before submission.

Competing Financial Interests

The authors declare no competing financial interest. 
contribute directly to HIV-1-associated B cell dysfunction. Our studies provide a mechanism whereby the virus may subvert the early HIV-1-specific humoral immune response.

During the course of HIV-1 infection persistent viral replication leads to a gradual and progressive loss of $\mathrm{CD}^{+} \mathrm{T}$ cells together with an aberrant, generalized and chronic activation of the immune system. This aberrant immune activation affects the viability, subset distribution, phenotype, and function of virtually all the major hematopoietic cell lineages ${ }^{1}$. Among the affected cell subsets are B cells, which exhibit numerous abnormalities that can be attributed to HIV-1-mediated chronic immune activation ${ }^{2,3}$. B cells isolated from viremic HIV-1-infected individuals spontaneously secrete high amounts of immunoglobulins (Igs), respond poorly to B cell stimuli, and exhibit impaired costimulatory functions ${ }^{4-6}$. These functional defects have also been associated with a perturbation in the distribution and relative proportions of B cell subpopulations in vivo ${ }^{7}$. In viremic patients with advanced HIV disease, peripheral blood contains an expanded population of immature/transitional B cells, a population generally associated with lymphopenia ${ }^{8,9}$. In addition, such patients manifest an expanded population of tissue-like $\mathrm{CD} 21^{\mathrm{lo}}$ memory $\mathrm{B}$ cells in their blood that have atypically high expression of the inhibitory IgA receptor Fc Receptor-Like protein 4 (FcRL4) along with other inhibitory receptors ${ }^{10,11}$. Of note, HIV-1-specific B cells are enriched within this abnormal B cell subpopulation. Consistent with high expression of FcRL $4^{12}$ these cells proliferate poorly in response to B cell stimuli. Their presence in the blood is closely linked to ongoing viral replication because their frequency declines following the initiation of anti-retroviral therapy ${ }^{13}$.

Several recent studies report that defects in the humoral immune response are already present during acute HIV-1 infection. For example, gut-associated lymphoid tissue (GALT) memory B cells from acutely infected individuals secrete autoreactive antibodies. Additionally GALT follicular damage and/or germinal center loss is seen in the terminal ileum and Peyer's patches soon after infection ${ }^{14,15}$. Most importantly, the initial HIVspecific antibody response is delayed, and can only be detected in plasma 2-5 weeks posttransmission ${ }^{16-20}$. In contrast to other viruses ${ }^{16,21,22}$ autologous neutralizing antibodies to HIV-1 do not become detectable until approximately 12 weeks after transmission and the appearance of broadly neutralizing antibodies (BnAbs) is greatly delayed and present in only approximately $20 \%$ of infected individuals ${ }^{17}$. The mechanisms underlying these delayed antibody responses are not known, but are likely critical to our understanding of the evolution of BnAbs to HIV-1 infection. Identifying these mechanisms is a central issue relevant to the design and development of vaccine immunogens capable of eliciting BnAbs. Here we identify a novel mechanism by which the HIV-1 envelope protein gp120, by engaging the integrin receptor $\alpha_{4} \beta_{7}$, exerts a profoundly negative impact on B cell function.

\section{RESULTS}

\section{B cells express $\alpha_{4} \beta_{7}$ and bind gp120}

We isolated human B cells from peripheral blood mononuclear cells (PBMCs) from several different donors and tested their baseline expression of $\alpha_{4} \beta_{7}$ by flow cytometry employing anti- $\beta_{7}$ (FIB504) and anti- $\alpha_{4} \beta_{7}$ specific for the heterodimer (Act-1). Human peripheral blood 
B cells, constitutively express $\alpha_{4} \beta_{7}$ (Fig. 1a) ${ }^{23}$. We did note donor variability, as some individuals expressed more than others (Fig. 1b) both in terms of frequency and mean density. To verify that the $a_{4} \beta_{7}$ on peripheral blood B cells functions as an integrin receptor, we tested whether it could bind its natural ligand mucosal vascular addressin cell adhesion molecule 1 (MAdCAM-1). We found substantial binding of soluble MAdCAM-1 to $\alpha_{4} \beta_{7}$ expressing B cells, which decreased in the presence of mAb 2B4 that reacts with the $a_{4}$ chain of the heterodimeric $\alpha_{4} \beta_{7}$ molecule and is known to compete with MAdCAM-1 binding (Fig. 1c).

Having established that freshly isolated human blood B cells expressed functional $\alpha_{4} \beta_{7}$, we tested whether recombinant HIV-1 gp120 could also bind $\alpha_{4} \beta_{7}$ on freshly isolated primary B cells. Because divalent cations regulate the activation state of the integrin and thereby influence the binding of gp120 to $\alpha_{4} \beta_{7}$, we included divalent cations in the binding buffer ${ }^{24}$. The gp120 employed for the binding assay was derived from an early viral isolate (R66M) subtype A/C. This gp120 bound to B cells and the binding was markedly reduced upon removal of the divalent cations from the buffer (Fig. 1c). The gp120 R66M bound significantly better to B cells from donors that expressed relatively higher amounts of $a_{4} \beta_{7}$ (Fig. 1b). Two specific mAbs against the $a_{4}$ integrin chain also inhibited gp120 binding to $a_{4} \beta_{7}$ on B cells although not always to baseline (Fig. 1b-d). These findings indicate that the majority of the gp120 binding to B cells is $\alpha_{4} \beta_{7}$-mediated, although other interactions cannot be excluded. In separate experiments we tested several gp120 envelopes from HIV-1 subtypes A, B and C: all exhibited reactivity for $\alpha_{4} \beta_{7}$, but with varying degrees. Other studies have reported that HIV-1 gp120 binds to human B cells. A previous report found that HIV-1 gp120 binds to C-type lectins expressed on activated human B cells inducing Ig class switching and increased expression of activation-induced cytidine deaminase ${ }^{25}$. However, this is the first study demonstrating HIV-1 gp120 binding to freshly isolated B cells in the absence of activation. Together our results indicate that most peripheral blood B cells express $\alpha_{4} \beta_{7}$ and that gp120s from each of the major subtypes bind to B cells via an interaction involving $\alpha_{4} \beta_{7}$.

\section{T-independent stimulation is suppressed by gp120}

Naïve and effector lymphocytes use $\alpha_{4} \beta_{7}$ to extravasate from the blood to gut mucosal tissues by interacting with endothelial MAdCAM-1 (ref. ${ }^{26}$ ). In addition, $\alpha_{4} \beta_{7}$ functions as a co-stimulatory receptor on GALT B cells where it engages MAdCAM-1 expressed on follicular dendritic cells in Peyer's patches and mesenteric lymph nodes ${ }^{27,}{ }^{28}$. gp120 can transduce signals through $\alpha_{4} \beta_{7}$ on primary $C D 4^{+} T$ cells ${ }^{24}$. Having shown that gp120 can also bind $\alpha_{4} \beta_{7}$ on primary $\mathrm{B}$ cells, we tested whether gp120 can induce signal transduction through $\alpha_{4} \beta_{7}$ on B cells, resulting in altered function. Purified B cells were CFSE-labeled and then treated with anti-IgM along with the Toll-Like Receptor 9 (TLR9) ligand CpG, which together mimic T-independent (TI) B cell activation, in the presence of either a gp120 that binds strongly to $a_{4} \beta_{7}$ (R66M) (Fig. 1b-d) or as a control a second gp120 that shows minimal binding to $\alpha_{4} \beta_{7}(92 \mathrm{Th} 14.12)$ (Fig. 1d). After 4 days, cells were stained with CD19 and examined by flow cytometry for their dilution of CFSE. As expected, anti-IgM plus $\mathrm{CpG}$ induced a strong proliferative response, with only $\sim 16 \%$ of the cells having not diluted their CFSE. Some cells exhibited an 8-fold CFSE dilution (Fig. 2a, left). The inclusion of 
R66M gp120 (high reactivity for $\alpha_{4} \beta_{7}$ ) along with anti-IgM plus CpG led to an abortive proliferative response (Fig. 2a, middle) while exposure to $92 \mathrm{Th} 14.12 \mathrm{gp} 120$ (minimal $\mathrm{a}_{4} \beta_{7}$ reactivity) had no effect (Fig. 2a, right). 45\% of the R66M gp120-exposed cells did not dilute their CFSE and most of the cells that responded, diluted it only 2-fold (Fig. 2a, middle) while the CFSE dilution pattern of the $92 \mathrm{Th} 14.12$ gp120-treated cells resembled that of the activated control (Fig. 2a, right). $\alpha_{4} \beta_{7}$-reactive gp120 significantly reduced proliferation as indicated by the change in division index $\mathrm{p}<0.001$ (Fig. 2b). Additionally R880F gp120, another envelope with a high reactivity for $\alpha_{4} \beta_{7}$ (Fig. 1c), inhibited B cell proliferation in a dose-dependent manner (Fig. 2c).

Despite the block in proliferation that occurred when cells were stimulated in the presence of $\alpha_{4} \beta_{7}$-reactive gp120, light scatter revealed an increase in the size of B cells consistent with cellular activation (Fig. 2d), with only a minor increase ( 10\%) in cell mortality after $72 \mathrm{~h}$. This indicates that gp120 was not blocking early stages of cell division. To address this issue treated B cells were stained with propidium iodide (PI) and subjected to analysis by flow cytometry. We found that a large fraction of cells entered G1/S but were blocked from entering G2/M (Fig. 2e). Thus gp120 treatment does not act on B cells at the early stages of cell cycle but inhibits proliferation at G1/S phase with a minor effect on survival.

\section{gp120-mediated gene expression in B cells}

To better understand the mechanisms by which the $\alpha_{4} \beta_{7}$-gp120 interaction affects primary human B cells we performed an oligonucleotide microarray analysis using human B cells exposed to different gp120s or a mock protein preparation. In the first set of experiments, we employed two closely related gp120s isolated from a single patient ${ }^{29}$. Z205F 0M gp120, which binds strongly to $\alpha_{4} \beta_{7}$, was derived from an HIV-1 subtype C-infected individual within the first month (0M) of infection. Z205F 38M gp120 was isolated from the same patient 38 months (38M) after infection and this gp120 showed low but detectable $\alpha_{4} \beta_{7^{-}}$ reactivity ${ }^{30}$. As expected these two envelopes differentially bound peripheral blood B cells in an $\alpha_{4} \beta_{7}$-dependent manner (Fig. 3a). Freshly isolated unstimulated B cells from three different normal donors were treated with each of the two gp120s. The gp120-mediated transcriptional pattern was measured at three time points $(0.5,3$ and $6 \mathrm{~h}$ ) (Fig. $3 \mathrm{~b})$. The hierarchical clustering of sample groups shows that the affinity of the gp120 for $\alpha_{4} \beta_{7}$ was a strong factor driving gene expression (Fig. 3b), as gene expression profiles generated in different donors by exposure to $\mathrm{Z} 205 \mathrm{~F} 0 \mathrm{M}$ (strong $\alpha_{4} \beta_{7}$ reactivity) clustered together (Fig. $3 b)$. The sample groups were further subclustered based on time, as indicated by the dendrogram (Fig. 3b). Two major clusters were identified: cluster 1 includes upregulated genes and cluster 2 is comprised of down-modulated genes (Fig. 3b). Approximately 500 genes in primary B cells were affected by treatment with gp120. The degree of modulation in the two major clusters appeared to be proportional to the $\alpha_{4} \beta_{7}$-reactivity of the gp120 employed. Most of the genes significantly modulated by gp120 treatment were those encoding proteins associated with chemotaxis, regulation of apoptosis, regulation of lymphocyte proliferation and immune/inflammatory responses (Table 1).

Among the various induced genes identified by this microarray analysis were those cytokine and chemokine genes that encode Tumor Necrosis Factor (TNF), Interleukin $1 \beta(I L I B)$ and 
Transforming Growth Factor- $\beta 1$ (TGFB1). In addition to TGF- $\beta 1$, gp120 modulated expression of several components of the TGF- $\beta$ pathway including SMAD6 and SMAD7. HIV-1 gp120 also impacted a variety of genes involved in B cell activation and differentiation including $C D 86, C D 27, C D 38, C D 83$, B-Cell Lymphoma 6 protein (BCLO), Regulator of G-protein Signaling 1 ( $R G S 1)$, and p21 gene Cyclin-Dependent Kinase inhibitor 1A (CDKN1A). Of note, we also detected an increase in the expression of Integrin Alpha 5 (ITGA5), which encodes the a integrin subunit that forms the heterodimer that binds fibronectin ${ }^{31}$. Another gene significantly up-regulated by gp120 treatment of B cells was FCRL4, which encodes an inhibitory receptor expressed on a subset of memory B cells that is up-regulated in the peripheral blood of HIV-1-infected individuals and in the peripheral blood of individuals with chronic malaria infection ${ }^{10,32-34}$. To verify the altered gene expression profile identified by microarray analysis we used real-time PCR (RT-PCR) to cross-check select genes of interest. These included the mRNAs for IL1B, TNFAIP6, TGFB1, SMAD6, SMAD7, ITGA5 and FCRL4 (Fig. 3c). Of note the degree of gene upregulation detected by PCR analysis was consistently higher than that observed in our microarray analysis, indicating that the latter method underestimated the actual changes in transcription. These data indicate that the exposure of peripheral blood B cells to HIV-1 gp120 alters the transcriptional pattern of many genes involved in inflammation and B cell function. Furthermore, expression of these genes was altered more by gp120 with a relatively high affinity for $\alpha_{4} \beta_{7}$ compared to a form that exhibits low $\alpha_{4} \beta_{7}$-reactivity.

\section{gp120-mediated gene expression in activated B cells}

Next, we carried out a similar analysis; however, in this case we stimulated the B cells with a TI inductive signal in the presence or absence of gp120. We employed the same two envelope proteins we used in the initial binding assays, R66M (high affinity for $\alpha_{4} \beta_{7}$ ) and 92Th14.12 (negative/low affinity) (Fig. 4a). We treated B cells from three different normal donors with gp120 and analyzed gene expression $6 \mathrm{~h}$ post gp120 treatment. We found $>500$ mRNA transcripts modulated by treatment with gp120 (Fig. 4b). Proteins encoded by these mRNAs were grouped in the following categories: regulation of apoptosis, immune response, leukocyte proliferation, regulation of lymphocyte activation and differentiation (Table 2). gp120 treatment of the activated B cells altered the transcription pattern of many of the same genes that we had noted in the first microarray using unstimulated B cells. These included TGFB1, SMAD7 and CDKN1A (p21) as well as genes involved in the TGF- $\beta$ pathway including Bone Morphogenetic Protein (BMP) receptor, Suppressor of cytokine signaling 1 (SOCS1), Latent TGF- $\beta$ Binding Protein 3 (LTBP3). FCRL4 is another gene that appeared up-regulated in both the first and second analysis (Fig. 4c). Of note the activation alone induced a 4-fold increase in FCRL4 mRNA expression as compared to un-stimulated B cells. However, the inclusion of R66M gp120 increased FCRL4 mRNA abundance an additional 8-fold, while the treatment of cells with the 92Th14.12 envelope had no effect (Fig. 4c). These results along with the results generated using unstimulated B cells prompted further investigation of several genes involved in B cell activation, the TGF- $\beta 1$ pathway and FcRL4, whose increased expression might be involved in gp120-mediated inhibition of proliferation shown in (Fig. 2) ${ }^{12}$. 


\section{gp120-mediated modulation of CD80 and FcRL4 expression}

An effective humoral response requires cognate B-T cell interactions. In this context one of the key co-stimulatory interactions involves CD80 and CD86 expressed on activated B cells and $\mathrm{CD} 28$ expressed on responder $\mathrm{CD} 4^{+}{ }^{\mathrm{T}}$ cells ${ }^{35}$. In vitro-stimulated $\mathrm{B}$ cells from HIVinfected viremic individuals up-regulate $\mathrm{CD} 80$ and $\mathrm{CD} 86$ poorly relative to healthy donors ${ }^{6}$, and germinal center B cells of HIV-infected individuals exhibit low expression of CD80, but relatively normal expression of $\mathrm{CD} 86^{36}$. As our microarray analysis revealed a reduction in CD86 mRNA expression by gp120 treatment (Tables 1 and 2), we used flow cytometry to assess the surface expression of the co-stimulatory markers CD80 and CD86 following TI stimulation in the presence or absence of gp120.

When we added an HIV-1 gp120 that efficiently binds $\alpha_{4} \beta_{7}$ (R880F) the stimulated B cells poorly up-regulated their CD80 surface expression when compared to B cells stimulated in the absence of gp120 or in the presence of a weak binding variant (92Th14.12) (Fig. 5a). We tested in parallel over a time course two gp 120 s that bind $\alpha_{4} \beta_{7}$ with high affinity (R880F) or intermediate affinity (AN1) and each reduced the induction of CD80 protein expression (Fig. 5b). This gp120-mediated effect on cell-surface expression was specific for CD80, surprisingly no change in CD86 cell-surface expression was detected (Fig. 5c) despite its reduced mRNA expression (Tables 1 and 2).

FcRL4 is an IgA receptor whose expression on B cells is associated with an inhibition of B cell receptor (BCR) signaling 11, 12,37. In healthy individuals FcRL4 ${ }^{+} \mathrm{B}$ cells are primarily localized to mucosal tissues and mesenteric lymph nodes, and are rarely found in peripheral blood, peripheral lymph nodes, or spleen ${ }^{32,38}$. However, as noted above, in HIV-1 viremic individuals FcRL4 ${ }^{+} \mathrm{B}$ cells appear in peripheral blood ${ }^{10}$. Because gp120 increased FCRL4 mRNA in B cells we tested whether the increased surface expression of FcRL4 associated with viremia might be due to interaction of B cells with the viral envelope. We activated peripheral B cells with TI stimulation with or without gp120 and measured surface expression of FcRL4 by flow cytometry. As expected no basal expression of FcRL4 was detected on freshly isolated ( $0 \mathrm{~h}$ ) peripheral blood B cells (Fig. 6a), the majority of which are circulating CD27- naïve B cells (Supplementary Fig. 1). Consistent with our microarray analysis, 24h after TI stimulation peripheral B cells exhibited measurable FcRL4 expression on the cell surface; expression then declined such that by $72 \mathrm{~h}$ FcRL4 expression was similar to that of unstimulated cells (Fig. 6a). To our knowledge this is the first demonstration that FcRL4 is up-regulated by TI stimulation. The addition of an $\alpha_{4} \beta_{7}$-reactive gp120 (R880F) together with TI stimulation increased early induction of FcRL4 even further (mean increase $80 \%$, range increase $27-221 \%, n=7$ ). Moreover, the inclusion of gp120 resulted in prolonged expression of FcRL4, such that elevated expression was maintained at 72-96h post-treatment (Fig. 6b). When B cells were stimulated in the presence of a HIV-1 gp120 with intermediate affinity for $\alpha_{4} \beta_{7}$ (AN1), FcRL4 expression was induced and sustained but to a lower degree (Fig. 6c). We then assessed FcRL4 expression in relation to the proliferative status of the B cells using CFSE-labeled cells. 96h after TI stimulation, a large majority of B cells showed the expected proliferation (Fig. 6d, left), but as described above (Fig. 6a,b) at 72-96h there was little detectable surface expression of FcRL4 (Fig. 6d, left). In contrast, after $96 \mathrm{~h}$ the majority of B cells stimulated in the presence of highly $\mathrm{a}_{4} \beta_{7^{-}}$ 
reactive gp120 did not proliferate, but did express FcRL4 (Fig. 6d, middle, 6e). When we employed a gp120 that exhibits intermediate $\alpha_{4} \beta_{7}$-reactivity both the inhibition of proliferation and the up-regulation of FcRL4 were less pronounced (Fig. 6d, right). High FcRL4 expression on the surface of gp120-treated cells correlated with an inability of these cells to divide in response to TI stimulation. Together these data indicate that treatment of B cells with gp120 increases the expression of FcRL4 and limits the proliferative expansion of B cells in an $\alpha_{4} \beta_{7}$-dependent manner.

\section{Infected T cells induce B cell FcRL4}

Finally, we examined whether HIV-1 replication in $\mathrm{CD} 4^{+} \mathrm{T}$ cells could induce FcRL4 surface expression on bystander B cells. We stimulated and then infected, with a CCR5tropic virus, $\mathrm{CD}^{+} \mathrm{T}$ cells taken from an HIV-1-negative donor. After seven days freshly isolated autologous $\mathrm{B}$ cells were activated and added to the infected $\mathrm{CD} 4^{+} \mathrm{T}$ cell culture. We assessed FcRL4 expression by flow cytometry $48 \mathrm{~h}$ later. The infection efficiency was determined by p24 ELISA and by mAb A32 surface staining (Fig. 6f). By $48 \mathrm{~h}, \sim 40 \%$ of the $\mathrm{CD} 19^{+} \mathrm{B}$ cells from an infected T-B co-culture expressed high amounts of FcRL4 compared to only $\sim 20 \%$ of the B cells in the control uninfected T-B cell co-culture (Fig. 6g). Of note, the T-B cell co-culture induction of FcRL4 expression was somewhat variable among different donors (Fig. 6h). Thus, both treatment with gp120 and co-culture with HIV-1infected $\mathrm{CD} 4^{+} \mathrm{T}$ cells induced expression of FcRL4 on peripheral blood B cells.

\section{gp120-mediated TGF- $\beta 1$ secretion and expression of FcRL4}

By microarray analysis we found that gp120 treatment led to increased expression of TGFB1 mRNA, which we confirmed by RT-PCR (Table 1 and 2, Fig. 3 ). TGF- $\beta 1$ is produced by activated lymphocytes and can inhibit B cell proliferation ${ }^{39}$. Because gp120 suppresses proliferation induced by a TI inductive signal, we asked whether this effect was mediated by TGF- $\beta 1$. We first tested whether gp120 induces the secretion of active TGF- $\beta 1$ from activated B cells. We found that stimulated B cells from 3 separate normal donors cultured with an $\alpha_{4} \beta_{7}$-reactive gp 120 produced significantly more TGF- $\beta 1$ in culture supernatants than did activated cells alone (Fig. 7a). This observation along with the known role of TGF$\beta 1$ as an IgA switch factor ${ }^{40,41}$ and FcRL4 as an IgA Fc receptor ${ }^{11}$, prompted us to test whether TGF- $\beta 1$ might substitute for gp120 as an inductive signal for FcRL4 expression. We found that TGF- $\beta 1$ was able to recapitulate the gp120-mediated induction of FcRL4 surface expression (Fig. 7b), suggesting that gp120 induces FcRL4 via the induction of TGF- $\beta 1$. To determine whether this was the case we treated TI-stimulated B cells with gp120 in the presence or absence of an antibody to TGF- $\beta 1$ and found that inclusion of antiTGF- $\beta 1$ reversed gp120-mediated induction of FcRL4 (Fig. 7b, left) and down-modulated CD80 surface expression (Fig. 7b, right). To understand if the gp120-mediated inhibition of a proliferative response was also linked to induction of TGF- $\beta 1$ we included a TGF- $\beta 1$ specific $\mathrm{mAb}$ in a CFSE proliferation assay of activated B cells. The inclusion of a TGF- $\beta 1$ neutralizing antibody restored the proliferative capacity of stimulated B cells in the presence of gp120 (Fig. 7c). The addition of either an $\alpha_{4} \beta_{7}$-reactive gp120 or TGF- $\beta 1$ resulted in a significant inhibition of B cell proliferation as assessed by changes in the division index $P<$ 0.001 (Fig. 7d). We conclude that TGF- $\beta 1$ plays a central role in both the gp120-mediated induction of FcRL4 and the gp120-mediated inhibition of B cell proliferation. These results 
reveal a previously unknown relationship between TGF- $\beta 1$ and surface expression of FcRL4.

\section{T-dependent stimulation is suppressed by gp120}

We next asked whether gp120 would impact T-dependent (TD) B cell proliferation. We modeled TD B cell proliferation by stimulating B cells with anti-IgM plus $\mathrm{CpG}$ and an antiCD40 mAb ${ }^{42}$. We first checked whether an $\alpha_{4} \beta_{7}$-reactive gp120 would impact cell surface expression of CD80 and CD86. The TD stimulation strongly up-regulated both CD80 and CD86 surface expression (Fig. 8a,b) and, as observed with TI stimulation, the addition of gp120 suppressed the induction of CD80 but not CD86 (Fig. 8a,b). TD stimulation also upregulated surface expression of FcRL4 after 24h (Fig. 8c), which declined after 72h. Addition of an $\alpha_{4} \beta_{7}$-reactive gp120 further induced, and sustained over time (96h), FcRL4 expression (Fig. 8d, left) and suppressed CD80 expression (Fig. 8d, right), as we observed with TI stimulation (Figs. 5,6). A TGF- $\beta 1$ neutralizing mAb reversed the effects of gp120 on FcRL4 and CD80 expression, while the inclusion of TGF- $\beta 1$ alone recapitulated the gp120 effect (Fig. 8d). When CFSE-labeled B cells were stimulated with a TD inductive signal in the presence of an $\alpha_{4} \beta_{7}$-reactive gp120 (R66M), a large fraction (45\%) of B cells had not proliferated by $96 \mathrm{~h}$ (Fig. 8e,f). The inclusion of a TGF- $\beta 1$ neutralizing $\mathrm{mAb}$ rescued proliferation (Fig. 8e), whereas the inclusion of TGF- $\beta 1$ alone recapitulated the gp120 effect (Fig. 8e,f). We conclude that the impact of gp120 on TD stimulation of B cells was similar to that on TI stimulation, and that this effect was mediated by TGF- $\beta 1$.

Finally, we asked whether gp120 treatment would impact TI and TD stimulation of memory $\mathrm{B}$ cells in a manner similar to its effect on naïve B cells. We obtained CD27 ${ }^{+} \mathrm{B}$ cells from fresh PBMCs preparations by bead selection. We observed donor to donor variability in $\beta_{7}$ expression (Supplementary Fig. 2a). An $\alpha_{4} \beta_{7}$-reactive gp120 (R66M) modestly reduced CD80 surface expression when included in a TI stimulation of $\mathrm{CD} 27^{+}$memory B cells (Supplementary Fig. 2b). A similar modest effect was observed upon TD stimulation (Supplementary Fig. 2b). As in naïve B cells, CD86 surface expression was not reduced (Supplementary Fig. 2c). However, for both TI and TD stimulation, an $\alpha_{4} \beta_{7}$-reactive gp120 (R66M) did up-regulate FcRL4 surface expression (Supplementary Fig. 2d). When CFSElabeled B cells were stimulated with a TI inductive signal in the presence of an $\alpha_{4} \beta_{7}$-reactive gp120 (R66M), 20\% of B cells did not proliferate by 96h (Supplementary Fig. 2e, f). When CFSE-labeled B cells were stimulated with a TD inductive signal in the presence of R66M gp120, only $\sim 5 \%$ of the cells failed to proliferate by $96 \mathrm{~h}$ (Supplementary Fig. $2 \mathrm{~g}, \mathrm{~h}$ ). Treatment of CD27+ memory B cells from 5 independent donors resulted in 5-20\% inhibition of proliferation compared to a $45-65 \%$ inhibition of proliferation in similarly treated naïve B cells. We conclude that an $\alpha_{4} \beta_{7}$-reactive gp120 affects memory B cell responses to TI and TD in a relatively modest way when compared to the suppressive effect we observed with naïve B cells.

\section{DISCUSSION}

In this report, we show that binding of HIV-1 gp120 to human B cells via integrin $\alpha_{4} \beta_{7}$ severely interferes with the activation and proliferation of B cells. Also, gp120 induces an 
$a_{4} \beta_{7}$-dependent pattern of gene expression in B cells that suggests an inhibitory effect. These findings point to a potentially important mechanism by which HIV-1 infection can directly impair B cell function. Specifically, gp120 impairs B cell function by activating inhibitory pathways that result in production of TGF- $\beta 1$, induction of FcRL4 and poor surface expression of the co-stimulatory molecule CD80.

It is well established that TGF- $\beta 1$ inhibits B cell activation and proliferation, both of which are essential for an efficient B cell response ${ }^{39,43}$. Moreover, overproduction of TGF- $\beta 1$ has been linked to lymph node fibrosis in HIV-infected individuals and SIV-infected monkeys ${ }^{44-46}$. Thus, the induction of TGF- $\beta 1$, by virions and/or free gp120 may interfere with Ig production, isotype switching, affinity maturation and the generation of both plasma and memory B cells, all of which are strictly dependent on B cell proliferation $39,47,48$. Of note, a role for integrins in the regulation of TGF- $\beta 1$ has recently been described ${ }^{49}$. Supporting the relevance of this potential mechanism of B cell dysfunction in vivo, it has been reported that plasma from viremic individuals exhibits marked increases in concentrations of TGF- $\beta 1^{50,51}$.

Exposure of B cells to gp120 induces a second protein associated with B cell dysfunction, FcRL4, an inhibitory IgA receptor that is normally found on B cells in the GALT ${ }^{33,52}$. Moreover, gp120 potentiates induction of FcRL4 on B cells stimulated by TI or TD inductive signals. In HIV-1 viremic individuals FcRL4 is over-expressed on circulating B cells ${ }^{10}$. Its expression is linked to an inhibition of $\mathrm{B}$ cell proliferation in a manner that is not fully understood. Although it is unclear how overexpression of FcRL4 impacts B cell function, the capacity of gp120 to induce its expression is consistent with FcRL4 overexpression on B cells of chronically infected viremic individuals. Of note, we found that treatment of B cells with TGF- $\beta 1$ induced FCRL4 expression. Importantly, gp120-mediated block of proliferation and induction of FcRL4 was abrogated by inclusion of a TGF- $\beta 1$ neutralizing mAb. Thus, induction of FCRL4 is a result of gp120-mediated induction of TGF- $\beta 1$. In this regard, we also found that co-culture of B cells with autologous HIV-1infected $\mathrm{CD} 4^{+} \mathrm{T}$ cells induced $\mathrm{B}$ cells to up-regulate FcRL4, supporting the concept of a direct link between viremia, TGF- $\beta 1$ induction and FcRL4 up-regulation. This finding is not only relevant for the HIV-1 field, but also for understanding the role of TGF- $\beta 1$ and FcRL4 in the activation and proliferation of $\mathrm{B}$ cells.

Binding of gp120 to B cells not only impairs the activation and proliferation of naïve B cells, but also affects their ability to function as antigen presenting cells by preventing the expression on the cell surface of the co-stimulatory molecule CD80. Aberrant expression of the co-stimulatory receptors CD80 and CD86 have previously been described in HIV-1 viremic individuals ${ }^{6}$. These defects likely contribute to the lack of an efficient humoral response in HIV-1-infected subjects. When B cells isolated from healthy individuals are stimulated in vitro, both CD80 and CD86 expression are induced, but B cells derived from HIV-1 viremic individuals fail, upon stimulation, to up-regulate these co-stimulatory receptors ${ }^{6}$. In addition, the expression of CD80 in germinal center B cells is reduced in viremic individuals ${ }^{36}$. We found a similar response in B cells exposed to gp120 in vitro such that stimulated B cells up-regulated CD80 expression in the absence, but not in the presence of gp120. Treatment of B cells with gp120 in vitro modulates CD80 expression in a manner 
similar to the way in which viremia impacts CD80 expression. Like gp120-mediated induction of FCRLA expression, the reduced CD80 surface expression depends upon TGF$\beta 1$ production.

In summary, we have demonstrated that HIV- 1 gp120 binds directly to $\alpha_{4} \beta_{7}$ on primary B cells and that this interaction recapitulates certain B cell phenotypic and functional abnormalities that are detected in HIV-1 viremic individuals. It is likely that some of these defects are linked to aberrant immune activation associated with HIV-1 viremia. Indeed polyclonal B cell activation and poor $\mathrm{T}$ cell help can be correlated with aberrant immune activation in viremic individuals ${ }^{2}$. However many of these defects are transient insofar as they are reversed by antiretroviral therapy ${ }^{7}$. Therefore, it is reasonable to postulate that certain aspects of the defective humoral response in HIV-infected individuals ${ }^{7,16}$ result from direct interactions between virions and/or free gp120 and B cells ${ }^{25,53}$. Coincident with B cell hyperactivation, patients exhibit defects in mucosal IgA responses and a delay in virus-specific $\mathrm{Ab}$ affinity maturation ${ }^{20,54}$. The data presented here reveal that virions and/or free gp120 can directly impair naïve B cell activation and proliferation by releasing TGF- $\beta 1$ which in turn upregulates the inhibitory IgA receptor FcRL4. Of note, FcRL4 overexpression induced by gp120 may account for the inadequate mucosal IgA responses demonstrated in acute HIV-1 and SIV infection ${ }^{20,55-58}$. Because viremia usually peaks during acute infection, it is at this stage of HIV-1 disease that the impact of gp120 on naive B cell function is likely to be most pronounced. In particular, gp120 may blunt and delay the nascent humoral immune response to HIV-1, including the generation of high-affinity HIVspecific neutralizing antibodies (nAbs) ${ }^{47}$. Thus, we propose that the B cell dysfunction occurring in the early stages of HIV-1 infection may be caused by a direct interaction of HIV-1 gp120 with B cells, explaining at least in part the perplexing inadequacy of the initial humoral immune response to HIV-1 infection.

\section{Methods}

\section{Human blood and tissue samples}

PBMCs were collected from healthy donors through a NIH Department of Transfusion Medicine protocol that was approved by the Institutional Review Board of the National Institute of Allergy and Infectious Diseases, National Institutes of Health. Informed consent was written and was provided by study participants and/or their legal guardians.

\section{Primary cells and antibody reagents}

Freshly isolated PBMCs were obtained from healthy donors and separated by FicollHypaque. Purified $\mathrm{CD} 4^{+} \mathrm{T}$ cells, B cells or $\mathrm{CD} 27^{+} \mathrm{B}$ cells were obtained by negative or positive selection using magnetic beads (StemCell Technologies, Vancouver, Canada) to > 95\% purity, as determined by flow cytometry. Freshly isolated B cells were cultured in complete RPMI 1640 medium with 2\% L-glutamine-penicillin-streptomycin (Gibco) and $10 \%$ FBS, activated with $\mathrm{F}\left(\mathrm{ab}^{\prime}\right)_{2}$ fragments of goat anti-human IgM $(10 \mu \mathrm{g} / \mathrm{ml}$; Jackson ImmunoResearch Laboratories, Inc.) and CpG oligodeoxynucleotide $2006(2.5 \mu \mathrm{g} / \mathrm{ml}$; Sigma), anti-CD40 $(0.5 \mu \mathrm{g} / \mathrm{ml}$; clone CP-870,893) in the presence or absence of the gp120 envelope ( $4 \mu \mathrm{g} / \mathrm{ml})$. Recombinant human latent TGF- $\beta 1$ (R\&D) was added at a 
concentration of $60 \mathrm{ng} / \mathrm{ml}$ and blocking antibody to TGF- $\beta 1$ (TGF- $\beta 1 / 1.2$ antibody) (R\&D) or Normal Chicken IgY Control (R\&D) were added at a concentration of $5 \mu \mathrm{g} / \mathrm{ml}$. Measurement of TGF- $\beta 1$ concentrations in B cell culture supernatants were done in RPMI 1640 (no FBS added) in presence of anti-IgM + CpG for 24-48h. In B-T cell co-culture assays, cultured $\mathrm{CD}^{+} \mathrm{T}$ cells were activated with OKT3, IL-2 $(20 \mathrm{IU} / \mathrm{ml})$ and all trans retinoic acid (RA, $10 \mathrm{nM}$ ). RA was obtained from Sigma Chemical. Antibodies to integrins were purchased from $R \& D$ and Beckman Coulter.

\section{Flow cytometry}

The following antibodies were used for flow cytometry: anti-integrin $\beta 7$ PE (clone FIB504), anti-CD10 APC (clone HI10a), anti-CD19 FITC or APC (clone HIB19), anti-CD20 APC (clone L27), anti-CD27 APC (clone M-T271), anti-CD38 APC (clone HB7), anti-CD80 PE (clone L307.4), anti-CD86 APC (clone 2331), were purchased from BD Biosciences; antiCD23 FITC (clone M-L233) and anti-CD69 PE (clone FN50), were purchased from BD Pharmingen; anti-CD21 FITC (clone BL13) was purchased from Beckman Coulter; antihSiglec-2/CD22 PE (clone 219934), was purchased from R\&D Systems; anti-CD307d (FcRL4) PE (clone 413D12) was purchased from Biolegend; the mAb anti- $\mathrm{a}_{4} \beta_{7}$ heterodimer (clone Act-1) was provided by the NIH AIDS Research \& Reference Reagent Program and was PE-labeled using the LYNX Rapid Conjugation Kit (AbD Serotec).

Data were collected on FACSCanto (BD Biosciences) and were analyzed with FlowJo software.

\section{Recombinant envelope proteins}

The following gp120s were employed in these studies: R66M, Z1792M (sequence received through direct communication with C. Derdeyn, R5-tropic), R880F (JX096639), Z185F (GQ485314), 92Th14.12 (U08801), AN1 gp120 (sequence available at http:// ubik.mullins.microbiol.washington.edu/HIV/Doria-Rose2005/, R5-tropic. All gp120 coding sequences were synthesized and codon-optimized for expression in mammalian cells (DNA2.0, Menlo Park, CA). All recombinant proteins were produced and purified in an identical manner unless noted otherwise ${ }^{24}$. The mature coding sequences of each envelope protein, from +1 to the gp120-gp41 junction were inserted into a mammalian expression vector downstream of a synthetic leader sequence. Vectors were transiently transfected into CHO-S cells (Invitrogen) using FreeStyleTM MAX Reagent (Invitrogen) per the manufacturer's instructions. Protein containing supernatants were harvested $72 \mathrm{~h}$ post transfection and passed over a column of Galanthus nivalis lectin sepharose (Vector Labs), which was diluted 1:5 with unliganded sepharose $4 \mathrm{~B}$ to minimize avid binding. gp120 was eluted with $20 \mathrm{mM}$ Glycine-HCl, pH 3.0, $150 \mathrm{mM} \mathrm{NaCl}, 500 \mathrm{mM}$ a-methylmannopyranoside (Sigma), in $5 \mathrm{ml}$ fractions directly into $1 \mathrm{M}$ Tris-HCl, $\mathrm{pH}$ 8.0. Peak fractions were pooled, concentrated with a stirred cell concentrator (Millipore) and dialysed exhaustively against HEPES, pH 7.4, $150 \mathrm{mM} \mathrm{NaCl}$. For gp120 preparations that included higher m.w oligomeric forms a size-exclusion chromatography step was included (Supplementary Fig. 3). To eliminate possible endotoxin contamination from purified proteins a triton X114 extraction was performed ${ }^{24,59}$ Proteins were quantitated by UV 
adsorption at O.D. $\lambda 280$ (extinction coefficient 1.1) and values were confirmed by a bicinchoninic acid protein assay (Thermo Scientific).

\section{Recombinant gp120 protein labeling}

Purified recombinant gp120s were biotinylated using amine-coupling chemistry. To eliminate possible endotoxin contamination from purified proteins, it is performed a triton X114 extraction ${ }^{24,59}$. Proteins were reacted with a 100-fold molar excess of EZ-Link NHSBiotin (Thermo Scientific) for $30 \mathrm{~min}$, and reactions were quenched by rapid bufferexchange into HBS, $\mathrm{pH}$ 7.4. biotin incorporation was determined by reacting gp120s with 4'-hydroxyazobenzene-2-carboxylic acid-avidin conjugates (HABA) per the manufacturers' instructions (Thermo Scientific). Protein preparations exhibiting 1.0-1.2 moles biotin/gp120 incorporation were used in comparative semi-quantitative flow-cytometric binding assays.

\section{Flow cytometry binding assays}

B cell staining with gp120 was carried out in a $10 \mathrm{mM}$ HEPES, $150 \mathrm{mM} \mathrm{NaCl}$ (HBS Buffer) buffer containing $100 \mu \mathrm{M} \mathrm{CaCl}_{2}, 1 \mathrm{mM} \mathrm{MnCl}_{2}$, and 5\% BSA. Cells were pre-blocked with normal mouse IgG and human IgG (5 $\mu$ g each, per $1 \times 10^{6}$ cells $) .2 \times 10^{5}$ cells were stained in a volume of $100 \mu \mathrm{l}$ on ice. Where indicated $\alpha_{4} \beta_{7}$-gp120 interactions were masked with 5 $\mu \mathrm{g}$ unlabeled $\mathrm{a}_{4} \mathrm{mAb} 2 \mathrm{~B} 4$ (R\&D) and HP2/1 (Beckman Coulter). Masking antibodies were not washed away prior to gp120 staining. Biotinylated gp120 was added for $25 \mathrm{~min}$ on ice, after which cells were washed twice with staining buffer. In each stain CD19 FITC (Becton Dickinson) was included, as well as Neutravidin PE (Invitrogen) followed by an additional $25 \mathrm{~min}$ incubation at room temperature. Cells were washed three times in staining buffer and then fixed in a $1 \%$ paraformaldehyde solution. Data were acquired using a BD FACSCanto and the PE mean fluorescence intensity measurements were obtained from the CD19+ gate. For gp120s that exhibited low or undetectable $\alpha_{4} \beta_{7}$ reactivity we note the possibility that the lack of reactivity may reflect features associated with expression in $\mathrm{CHO}$ cells (e.g. glycosylation) and that the same protein expressed in primary $\mathrm{CD}^{+} \mathrm{T}$ cells might exhibit detectable $\alpha_{4} \beta_{7}$ reactivity.

\section{Proliferation assay}

B cell proliferation was evaluated by dilution of the vital dye CFSE. CFSE labeling was performed by using the CellTrace CFSE Cell Proliferation Kit according to the manufacturer's instructions (Invitrogen). B cells were washed twice in PBS, resuspended in PBS containing 5-(and-6-) carboxyfluorescein diacetate succinimidyl ester (CFSE) at a final concentration of $0.5 \mu \mathrm{M}$, and incubated at R.T. for $10 \mathrm{~min}$. Labeled cells were washed three times with RPMI 10\% FBS and cultured in complete medium for 4 days. Proliferating CD19-positive B cells were identified by diluted CFSE content by flow cytometry.

\section{Cell cycle analysis}

$10^{5}$ activated (anti-IgM+CpG for $48 \mathrm{~h}$ ) B cells were washed in PBS and were fixed in $70 \%$ ethanol for 10-15 min at $4^{\circ} \mathrm{C}$. After two washes in PBS, was added RNase A for $15 \mathrm{~min}$ at $37^{\circ} \mathrm{C}$. After two washes in PBS, cells were stained with $10 \mu \mathrm{g} / \mathrm{ml}$ propidium iodide. They were then analyzed by flow cytometry. 


\section{HIV-1 infection}

An envelope (BG505.W6M.ENV.C2 Accession \#DQ208458) was introduced into a fulllength proviral clone of NL4-3. Viruses were produced by transient transfection into $293 \mathrm{~T}$ fibroblasts. Viral stocks were normalized by p24 antigen concentration with an enzymelinked immunoassay of p24 antigen (Perkin-Elmer), and then were used to infect CD4 ${ }^{+} \mathrm{T}$ cells cultured for at least 5 days in IL-2, OKT3 and retinoic acid (RA). Viral replication was measured by intracellular p24 staining (mAb RD1; Beckman Coulter), and by A32 mAb (anti-gp120) surface staining.

\section{In vitro co-culture of B cells with HIV-1 infected autologous CD4+}

Stimulated $\mathrm{CD}^{+}{ }^{+} \mathrm{T}$ cells isolated from an HIV-negative donor with anti-CD3, IL2 and retinoic acid (RA) for five days at which point cells were infected with a CCR5-tropic virus (see above). After seven days freshly isolated autologous B cells were treated with anti-IgM $+\mathrm{CpG}$ and added to the infected $\mathrm{CD} 4^{+} \mathrm{T}$ cell culture.

\section{TGF- $\beta 1$ ELISA}

Freshly isolated primary B cells were isolated from PBMCs. Cells were cultured in 48-well plates at a concentration of $5 \times 10^{5}$ per well in medium supplemented with anti-IgM and $\mathrm{CpG}$ with or without recombinant gp120 for $24-48 \mathrm{~h}$. TGF- $\beta 1$ production was measured in the culture supernatant employing a TGF- $\beta 1$ ELISA kit (R\&D) according to the manufacturer's instructions.

\section{Affymentrix sample fragment label and Human GeneArray}

Fragmentation and labeling of single-stranded cDNA. The Affymetrix Whole Transcript (WT) Terminal Labeling Kit is used for this step. $5.5 \mu \mathrm{g}$ of hydrolyzed cDNA from each sample was mixed with uracil-DNA glycosylase (UDG) and apurinic/apyrimidinic endonuclease 1 (APE1) and buffers in total of $50 \mu \mathrm{l}$ volume for the fragmentation in thermal cycler at the following condition: $37^{\circ} \mathrm{C}, 60 \mathrm{~min} ; 93^{\circ} \mathrm{C}, 2 \mathrm{~min} ; 4^{\circ} \mathrm{C}$, minimum $2 \mathrm{~min} .1 .0 \mu \mathrm{l}$ of the fragmented samples is analyzed on an Agilent Bioanalyzer RNA 6000 Nano chip. 45 $\mu \mathrm{l}$ of fragmented samples was mixed with terminal deoxynucleotidyl transferase (TdT) and other reagents, then incubated at $37^{\circ} \mathrm{C}, 60 \mathrm{~min} ; 70^{\circ} \mathrm{C}, 10 \mathrm{~min}$ and then $4^{\circ} \mathrm{C}$, hold. The final fragmented and terminal labeled products were hybridized on a human WT Exon array.

\section{Array Hybridization, Washing, Staining, and Scanning}

We employed an Affymetrix GeneChip ${ }^{\circledR}$ Hybridization, Wash and Stain Kit (P/N 900720). $5.5 \mu \mathrm{g}$ of fragmented and labeled samples were mixed with hybridization control and reagents in final volume of $220 \mu$. The hybridization cocktail was heated at $99^{\circ} \mathrm{C}$ for $5 \mathrm{~min}$; cooled to $45^{\circ} \mathrm{C}$ for $5 \mathrm{~min}$; and centrifuged at maximum speed for $1 \mathrm{~min}$. The GeneChip Array was equilibrated to room temperature before use. $200 \mu \mathrm{l}$ of hybridization cocktail was injected into the array for each sample and incubated in a $45^{\circ} \mathrm{C}$ hybridization oven, at 60 $\mathrm{rpm}$, for $17 \mathrm{~h} \pm 1 \mathrm{~h}$. A sample file was registered in Affymetrix GeneChip Command Console (AGCC) to wash, stain, and scan a probe array. Each array was washed and stained in Affymetrix fluidics 450 . The probe array was scanned in an Affymetrix ${ }^{\circledR}$ GeneChip ${ }^{\circledR}$ Scanner $30007 \mathrm{G}$. 


\section{Microarray Data Analysis}

Partek Genomics Software 2.3 (http://www.partek.com) was used for statistical analysis.

Raw intensity data were normalized using RMA and an quantile normalization method.

Differentially regulated gene candidates were selected with two criteria: at least one of the fold changes among the treatment pairs must have been greater than or equal to 0.6 (positive affinity vs. negative affinity) or 0.7 (treatment vs. mock). The direction (up or down) of the fold changes was determined to be consistent among the three repeat samples. The selected genes were further clustered by the K-mean method and displayed in the heat map visualization by Partek. Gene functional annotation analysis was performed using DAVID Bioinformatics Tool (http://david.abcc.ncifcrf.gov). The microarray raw data has been archived in NCBI GEO database with accession No. GSE49019

\section{Real time PCR}

$500 \mathrm{ng}$ of total B cell RNA from 3 donors either mock-treated, or gp120-treated (6 hours) were reverse transcribed using a Taqman Reverse Transcription Reagent Kit (ABI) in a thermal cycler at $25^{\circ} \mathrm{C}$ for $10 \mathrm{~min}$, at $48^{\circ} \mathrm{C}$ for $30 \mathrm{~min}$, at $95^{\circ} \mathrm{C}$ for $5 \mathrm{~min}$ and held at $4^{\circ} \mathrm{C}$. Real time PCR primers and probes of genes of interest were obtained from ABI Assay-onDemand. The genes of interest and their Assay ID are listed in the below. Real time PCR was performed using a Taqman Gene Expression Master Mix (ABI) in a thermal cycler at $50^{\circ} \mathrm{C}$ for $2 \mathrm{~min}$, at $95^{\circ} \mathrm{C}$ for $10 \mathrm{~min}$ and 50 cycles at $95^{\circ} \mathrm{C}$ for $15 \mathrm{sec}$ and at $60^{\circ} \mathrm{C}$ for $1 \mathrm{~min}$. $G A P D H$ in each sample was employed as a control. Each gene was assayed in duplicate. Assay IDs for each gene are: RGS1 (Hs00175260_m1), JUN (Hs99999141_s1), FCRL4 (Hs00972783_m1), RGS16 (Hs00892674_m1), ITGA5 (Hs01547673_m1), SMAD6 (Hs00178579_m1), SMAD7 (Hs00998193_m1), TGFB1 (Hs00998133_m1), TNFAIP6 (Hs00200178_m1), CD86 (Hs01567025_m1), IL1B (Hs01555413_m1), IL8 (Hs99999034_m1), INHBA (Hs01081598_m1), GAPDH (HS99999905_m1). Real time PCR gene expression values (PCR cycle numbers) were normalized by subtracting corresponding expression levels of the internal control gene, GAPDH. The normalized gene expression values were used to calculate average fold.

\section{Statistical Analysis? \\ Supplementary Material}

Refer to Web version on PubMed Central for supplementary material.

\section{Acknowledgments}

We thank C. Derdeyn (Emory University, Atlanta, GA) for HIV sequence information. We thank A. Introini for useful suggestions. We thank J. Weddle and A. Weddle for assistance with figure preparation. This research was supported by the Intramural Research Program of the National Institutes of Health (National Institute of Allergy and Infectious Diseases). We apologize to any colleagues whose work we have not referenced directly due to space constraints.

\section{References}

1. Lawn SD, Butera ST, Folks TM. Contribution of immune activation to the pathogenesis and transmission of human immunodeficiency virus type 1 infection. Clin Microbiol Rev. 2001; 14:753-777. [PubMed: 11585784] 
2. Haas A, Zimmermann K, Oxenius A. Antigen-dependent and -independent mechanisms of T and B cell hyperactivation during chronic HIV-1 infection. J Virol. 2011; 85:12102-12113. [PubMed: 21849433]

3. Lane HC, et al. Abnormalities of B-cell activation and immunoregulation in patients with the acquired immunodeficiency syndrome. N Engl J Med. 1983; 309:453-458. [PubMed: 6224088]

4. Amadori A, De Rossi A, Faulkner-Valle GP, Chieco-Bianchi L. Spontaneous in vitro production of virus-specific antibody by lymphocytes from HIV-infected subjects. Clin Immunol Immunopathol. 1988; 46:342-351. [PubMed: 3257430]

5. De Milito A, et al. Mechanisms of hypergammaglobulinemia and impaired antigen-specific humoral immunity in HIV-1 infection. Blood. 2004; 103:2180-2186. [PubMed: 14604962]

6. Malaspina A, et al. Deleterious effect of HIV-1 plasma viremia on B cell costimulatory function. J Immunol. 2003; 170:5965-5972. [PubMed: 12794123]

7. Moir S, Fauci AS. B cells in HIV infection and disease. Nat Rev Immunol. 2009; 9:235-245. [PubMed: 19319142]

8. Cuss AK, et al. Expansion of functionally immature transitional B cells is associated with humanimmunodeficient states characterized by impaired humoral immunity. J Immunol. 2006; 176:15061516. [PubMed: 16424179]

9. Malaspina A, et al. Appearance of immature/transitional B cells in HIV-infected individuals with advanced disease: correlation with increased IL-7. Proc Natl Acad Sci USA. 2006; 103:2262-2267. [PubMed: 16461915]

10. Moir S, et al. Evidence for HIV-associated B cell exhaustion in a dysfunctional memory B cell compartment in HIV-infected viremic individuals. J Exp Med. 2008; 205:1797-1805. [PubMed: 18625747]

11. Wilson TJ, Fuchs A, Colonna M. Cutting edge: human FcRL4 and FcRL5 are receptors for IgA and IgG. J Immunol. 2012; 188:4741-4745. [PubMed: 22491254]

12. Sohn HW, Krueger PD, Davis RS, Pierce SK. FcRL4 acts as an adaptive to innate molecular switch dampening BCR signaling and enhancing TLR signaling. Blood. 2011; 118:6332-6341. [PubMed: 21908428]

13. Moir S, et al. Normalization of B cell counts and subpopulations after antiretroviral therapy in chronic HIV disease. J Infect Dis. 2008; 197:572-579. [PubMed: 18240953]

14. Levesque MC, et al. Polyclonal B cell differentiation and loss of gastrointestinal tract germinal centers in the earliest stages of HIV-1 infection. PLoS Med. 2009; 6:e1000107. [PubMed: 19582166]

15. Peruchon S, et al. Tissue-specific B-cell dysfunction and generalized memory B-cell loss during acute SIV infection. PLoS One. 2009; 4:e5966. [PubMed: 19543531]

16. Haynes BF, Moody MA, Liao HX, Verkoczy L, Tomaras GD. B cell responses to HIV-1 infection and vaccination: pathways to preventing infection. Trends Mol Med. 2011; 17:108-116. [PubMed: 21112250]

17. McMichael AJ, Borrow P, Tomaras GD, Goonetilleke N, Haynes BF. The immune response during acute HIV-1 infection: clues for vaccine development. Nat Rev Immunol. 2010; 10:11-23. [PubMed: 20010788]

18. Tomaras GD, Haynes BF. HIV-1-specific antibody responses during acute and chronic HIV-1 infection. Curr Opin HIV AIDS. 2009; 4:373-379. [PubMed: 20048700]

19. Shen X, Tomaras GD. Alterations of the B-cell response by HIV-1 replication. Curr HIV/AIDS Rep. 2011; 8:23-30. [PubMed: 21161615]

20. Yates NL, et al. HIV-1 gp41 envelope IgA is frequently elicited after transmission but has an initial short response half-life. Mucosal immunology. 2013 Vol. pages doi?

21. Naniche D. Human immunology of measles virus infection. Curr Top Microbiol Immunol. 2009; 330:151-171. [PubMed: 19203109]

22. Peacock DB, Jones JV, Gough M. The immune response to thetaX 174 in man. I. Primary and secondary antibody production in normal adults. Clin Exp Immunol. 1973; 13:497-513. [PubMed: 4197826]

23. Erle DJ, et al. Expression and function of the MAdCAM-1 receptor, integrin alpha 4 beta 7, on human leukocytes. J Immunol. 1994; 153:517-528. [PubMed: 7517418] 
24. Arthos J, et al. HIV-1 envelope protein binds to and signals through integrin alpha4beta7, the gut mucosal homing receptor for peripheral T cells. Nat Immunol. 2008; 9:301-309. [PubMed: 18264102]

25. He B, et al. HIV-1 envelope triggers polyclonal Ig class switch recombination through a CD40independent mechanism involving BAFF and C-type lectin receptors. J Immunol. 2006; 176:3931-3941. [PubMed: 16547227]

26. Gorfu G, Rivera-Nieves J, Ley K. Role of beta7 integrins in intestinal lymphocyte homing and retention. Curr Mol Med. 2009; 9:836-850. [PubMed: 19860663]

27. Szabo MC, Butcher EC, McEvoy LM. Specialization of mucosal follicular dendritic cells revealed by mucosal addressin-cell adhesion molecule-1 display. J Immunol. 1997; 158:5584-5588. [PubMed: 9190904]

28. Lehnert K, Print CG, Yang Y, Krissansen GW. MAdCAM-1 costimulates T cell proliferation exclusively through integrin alpha4beta7, whereas VCAM-1 and CS-1 peptide use alpha4beta1: evidence for "remote" costimulation and induction of hyperresponsiveness to B7 molecules. Eur J Immunol. 1998; 28:3605-3615. [PubMed: 9842903]

29. Rong R, et al. Escape from autologous neutralizing antibodies in acute/early subtype C HIV-1 infection requires multiple pathways. PLoS Pathog. 2009; 5:e1000594. [PubMed: 19763269]

30. Nawaz F, et al. The genotype of early-transmitting HIV gp120s promotes alpha (4) beta(7)reactivity, revealing alpha (4) beta(7) $+/ \mathrm{CD} 4+\mathrm{T}$ cells as key targets in mucosal transmission. PLoS Pathog. 2011; 7:e1001301. [PubMed: 21383973]

31. Margadant C, Monsuur HN, Norman JC, Sonnenberg A. Mechanisms of integrin activation and trafficking. Curr Opin Cell Biol. 2011; 23:607-614. [PubMed: 21924601]

32. Ehrhardt GR, et al. Expression of the immunoregulatory molecule FcRH4 defines a distinctive tissue-based population of memory B cells. J Exp Med. 2005; 202:783-791. [PubMed: 16157685]

33. Kuppers R. Human memory B cells: memory B cells of a special kind. Immunol Cell Biol. 2008; 86:635-636. [PubMed: 18695701]

34. Weiss GE, et al. Atypical memory B cells are greatly expanded in individuals living in a malariaendemic area. J Immunol. 2009; 183:2176-2182. [PubMed: 19592645]

35. Carreno BM, Collins M. The B7 family of ligands and its receptors: new pathways for costimulation and inhibition of immune responses. Annu Rev Immunol. 2002; 20:29-53. [PubMed: 11861596]

36. Legendre C, et al. CD80 expression is decreased in hyperplastic lymph nodes of HIV+ patients. Int Immunol. 1998; 10:1847-1851. [PubMed: 9885905]

37. Ehrhardt GR, et al. The inhibitory potential of Fc receptor homolog 4 on memory B cells. Proc Natl Acad Sci USA. 2003; 100:13489-13494. [PubMed: 14597715]

38. Falini B, et al. Expression of the IRTA1 receptor identifies intraepithelial and subepithelial marginal zone B cells of the mucosa-associated lymphoid tissue (MALT). Blood. 2003; 102:36843692. [PubMed: 12881317]

39. Kehrl JH, Thevenin C, Rieckmann P, Fauci AS. Transforming growth factor-beta suppresses human B lymphocyte Ig production by inhibiting synthesis and the switch from the membrane form to the secreted form of Ig mRNA. J Immunol. 1991; 146:4016-4023. [PubMed: 1903417]

40. Coffman RL, Lebman DA, Shrader B. Transforming growth factor beta specifically enhances IgA production by lipopolysaccharide-stimulated murine B lymphocytes. J Exp Med. 1989; 170:1039_ 1044. [PubMed: 2788703]

41. Sonoda E, et al. Transforming growth factor beta induces IgA production and acts additively with interleukin 5 for IgA production. J Exp Med. 1989; 170:1415-1420. [PubMed: 2677210]

42. Gantner F, et al. CD40-dependent and -independent activation of human tonsil B cells by CpG oligodeoxynucleotides. Eur J Immunol. 2003; 33:1576-1585. [PubMed: 12778475]

43. Kehrl JH, et al. Further studies of the role of transforming growth factor-beta in human B cell function. J Immunol. 1989; 143:1868-1874. [PubMed: 2550546]

44. Estes JD, Haase AT, Schacker TW. The role of collagen deposition in depleting CD4+ T cells and limiting reconstitution in HIV-1 and SIV infections through damage to the secondary lymphoid organ niche. Semin Immunol. 2008; 20:181-186. [PubMed: 18595731] 
45. Estes JD, et al. Simian immunodeficiency virus-induced lymphatic tissue fibrosis is mediated by transforming growth factor beta 1-positive regulatory $\mathrm{T}$ cells and begins in early infection. J Infect Dis. 2007; 195:551-561. [PubMed: 17230415]

46. Zeng M, et al. Cumulative mechanisms of lymphoid tissue fibrosis and T cell depletion in HIV-1 and SIV infections. J Clin Invest. 2011; 121:998-1008. [PubMed: 21393864]

47. Tangye SG, Hodgkin PD. Divide and conquer: the importance of cell division in regulating B-cell responses. Immunology. 2004; 112:509-520. [PubMed: 15270721]

48. Tangye SG, Ferguson A, Avery DT, Ma CS, Hodgkin PD. Isotype switching by human B cells is division-associated and regulated by cytokines. J Immunol. 2002; 169:4298-4306. [PubMed: 12370361]

49. Worthington JJ, Fenton TM, Czajkowska BI, Klementowicz JE, Travis MA. Regulation of TGFbeta in the immune system: an emerging role for integrins and dendritic cells. Immunobiology. 2012; 217:1259-1265. [PubMed: 22902140]

50. Kekow J, et al. Transforming growth factor-beta and suppression of humoral immune responses in HIV infection. J Clin Invest. 1991; 87:1010-1016. [PubMed: 1999481]

51. Wiercinska-Drapalo A, Flisiak R, Jaroszewicz J, Prokopowicz D. Increased plasma transforming growth factor-beta1 is associated with disease progression in HIV-1-infected patients. Viral immunology. 2004; 17:109-113. [PubMed: 15018667]

52. Polson AG, et al. Expression pattern of the human FcRH/IRTA receptors in normal tissue and in B-chronic lymphocytic leukemia. Int Immunol. 2006; 18:1363-1373. [PubMed: 16849395]

53. Qiao X, et al. Human immunodeficiency virus 1 Nef suppresses CD40-dependent immunoglobulin class switching in bystander B cells. Nat Immunol. 2006; 7:302-310. [PubMed: 16429138]

54. Tomaras GD, et al. Initial B-cell responses to transmitted human immunodeficiency virus type 1: virion-binding immunoglobulin $\mathrm{M}(\mathrm{IgM})$ and $\mathrm{IgG}$ antibodies followed by plasma anti-gp41 antibodies with ineffective control of initial viremia. J Virol. 2008; 82:12449-12463. [PubMed: 18842730]

55. Chaoul N, et al. Default in plasma and intestinal IgA responses during acute infection by simian immunodeficiency virus. Retrovirology. 2012; 9:43. [PubMed: 22632376]

56. Janoff EN, et al. Intestinal mucosal immunoglobulins during human immunodeficiency virus type 1 infection. J Infect Dis. 1994; 170:299-307. [PubMed: 8035014]

57. Mestecky J, et al. Paucity of antigen-specific IgA responses in sera and external secretions of HIVtype 1-infected individuals. AIDS research and human retroviruses. 2004; 20:972-988. [PubMed: 15585085]

58. Scamurra RW, et al. Mucosal plasma cell repertoire during HIV-1 infection. J Immunol. 2002; 169:4008-4016. [PubMed: 12244203]

59. Aida Y, Pabst MJ. Removal of endotoxin from protein solutions by phase separation using Triton X-114. J Immunol Methods. 1990; 132:191-195. [PubMed: 2170533] 
a
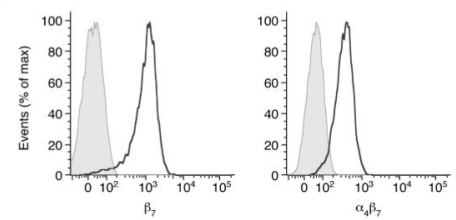

b

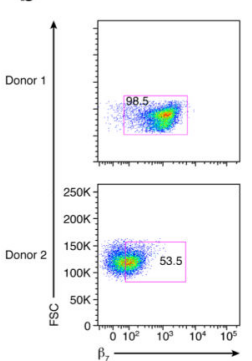

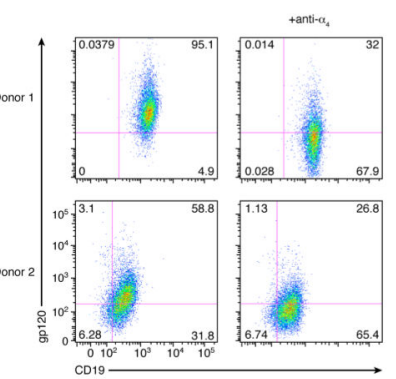

c

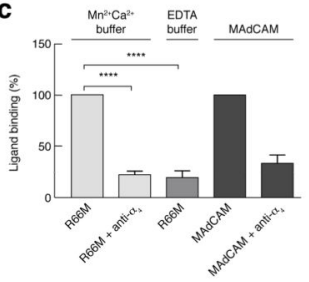

d

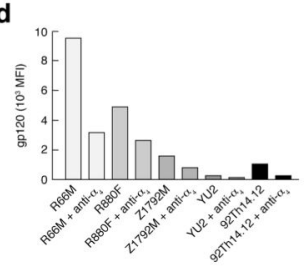

Figure 1.

MAdCAM-1 and HIV-1 gp120 bind to $\alpha_{4} \beta_{7}$ in a cation dependent manner. (a) $\alpha_{4} \beta_{7}$ expression detected by flow cytometry on freshly isolated primary B cells by an anti- $\beta_{7}$ and anti- $\alpha_{4} \beta_{7}$ (Act-1). (b) Variability of $\alpha_{4} \beta_{7}$ expression on B cells from two separate donors. Flow cytometry shows that the binding of R66M gp120 (derived from a patient within the first month of infection) is proportional to $\beta_{7}$ expression. $\beta_{7}$ gating is based on an isotype control for each donor. (c) Binding of R66M gp120 to $a_{4} \beta_{7}$ on B cells. R66M gp120 binding to $\mathrm{B}$ cells in the presence of $\mathrm{Ca}^{2+} / \mathrm{Mn}^{2+}+/-$ anti-a 4 (2B4), or in the absence of $\mathrm{Ca}^{2+} / \mathrm{Mn}^{2+}$ (EDTA buffer). MAdCAM-1 binding to $\mathrm{B}$ cells in the presence of $\mathrm{Ca}^{2+} / \mathrm{Mn}^{2+}+/-$ anti- $\mathrm{a}_{4}$ (2B4). Values reported indicate \% of binding normalized to R66M (or MAdCAM-1) binding (100\%), and are derived from 3 independent donors, $p<0.0001$ (one way ANOVA) (R66M $n=3$ ) (MAdCAM-1 $n=2$ ). (d) Comparison of the $\alpha_{4} \beta_{7}$-reactivity of a panel of five recombinant gp120 preparations. $\alpha_{4} \beta_{7}$-reactivity is reported as mean fluorescence intensity (MFI) of gp120s. An unlabeled anti-a 4 (2B4) was included as a specificity control. Results are representative of at least three independent experiments using $\mathrm{B}$ cells from different donors. 

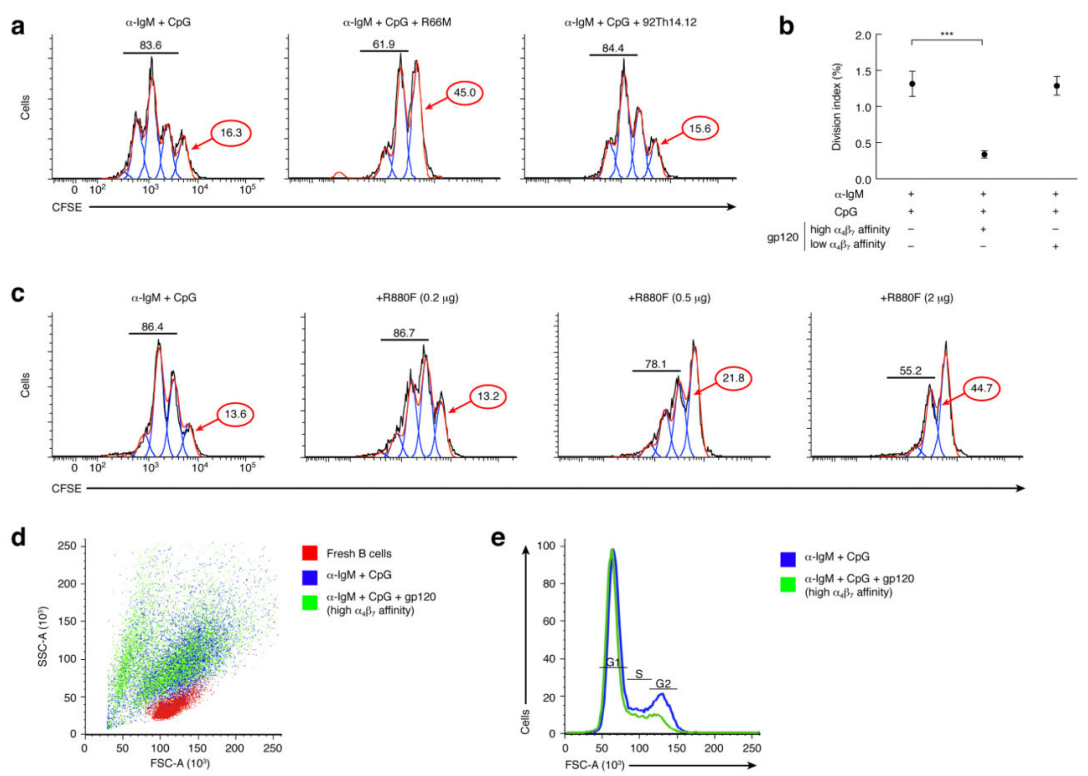

Figure 2.

An $\alpha_{4} \beta_{7}$-reactive gp120 inhibits a-IgM $+\mathrm{CpG}$ induced $\mathrm{B}$ cell proliferation. (a) CFSE proliferation assay of a-IgM $+\mathrm{CpG}$ induced proliferation of $\mathrm{B}$ cells in the presence of gp120s. An $a_{4} \beta_{7}$-reactive gp120 (R66M) blocks proliferation, while a gp120 with minimal affinity for $\alpha_{4} \beta_{7}$ (92Th14.12) fails to block proliferation. B cells were cultured with B cell stimuli (a-IgM $+\mathrm{CpG}$ ) with or without gp120s for 96 h. (b) Division Index (FlowJo) indicating the average number of cell divisions in cells from the original population from 5 independent donors. Treatment stimuli denoted below the $\mathrm{x}$-axis, $p<0.001$ (two-way ANOVA) ( $\mathrm{n}=5$ ). (c) A dose response utilizing three increasing concentrations of a gp120 with a high affinity for $\alpha_{4} \beta_{7}$ (R880F) were employed. (d) Light scatter overlay of freshly isolated (red), $\mathrm{a}-\operatorname{IgM}+\mathrm{CpG}$ stimulated (blue), and $\mathrm{a}-\operatorname{IgM}+\mathrm{CpG}+$ gp120 stimulated (green) B cells. (e) Flow-cytometry based cell cycle analysis of a-IgM $+\mathrm{CpG}$ stimulated (blue), and a-IgM $+\mathrm{CpG}+$ gp120-stimulated (green) B cells stained with PI (x-axis). Data reported are representative of three independent experiments. 
a

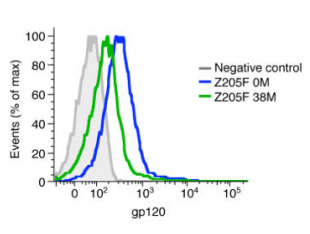

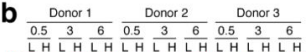

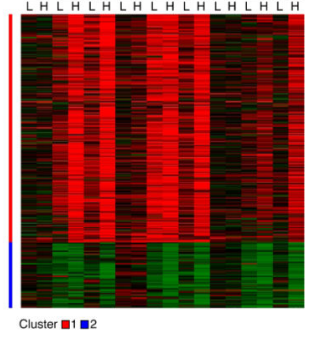

C

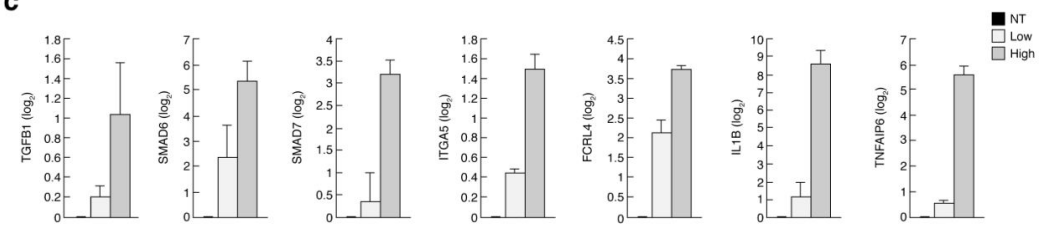

Figure 3.

HIV-1 gp120s with different affinity for $\alpha_{4} \beta_{7}$ affect gene expression of freshly isolated human B cells. (a) Flow cytometry shows the binding to human primary B cells of two gp120s employed for microarray analysis: Z205F 0M with a high affinity for $\alpha_{4} \beta_{7}$ and Z205F 38M with a low affinity for $\alpha_{4} \beta_{7}$. (b) Heat map visualization by Partek of gene expression modulation in response to treatment with month-0 gp120 (Z205F 0M with a high (H) affinity for $\left.\alpha_{4} \beta_{7}\right)$ and month-38 gp120 (Z205F 38M with a low (L) affinity for $\left.a_{4} \beta_{7}\right)$ isolated from a single patient. B cells from three normal donors were treated with the envelopes for $0.5,3$ and $6 \mathrm{~h}$. Statistical significance is reported relative to mock-treated B cells. Categories of the genes modulated by gp120- $\alpha_{4} \beta_{7}$ interaction are specified (DAVID Bioinformatics Tool). (c) PCR verification of gp120-induced genes in B cells. NT: mock, Low: gp120 with low $\alpha_{4} \beta_{7}$ affinity, High: gp120 with high $\alpha_{4} \beta_{7}$ affinity. Values are shown in fold increase over mock treated samples. Data reported are representative of three independent experiments. 
a

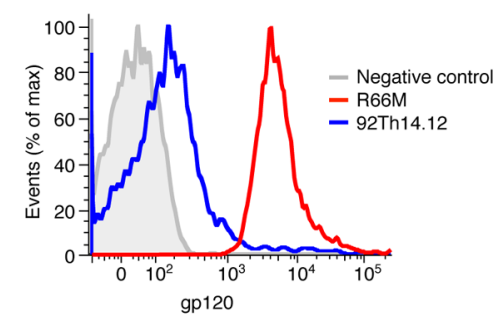

b

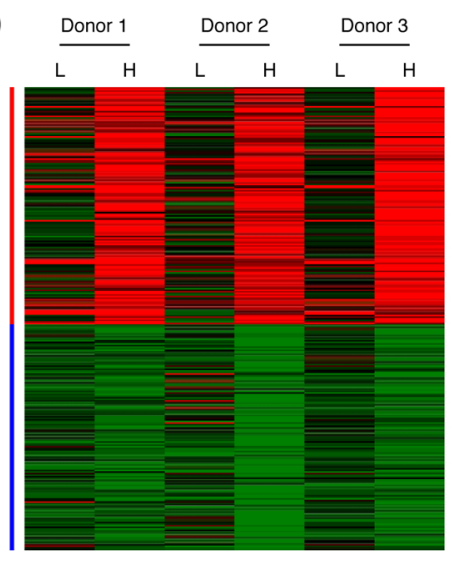

Cluster $\square 1$ a2
C

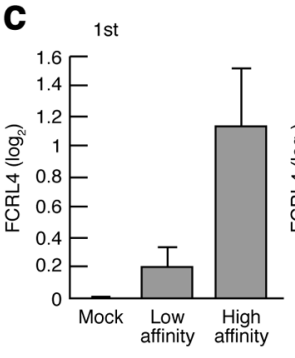

2nd

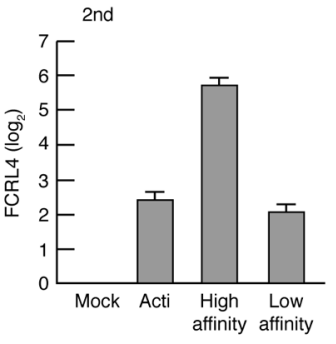

Figure 4.

HIV-1 gp120s with different affinity for $\alpha_{4} \beta_{7}$ affect gene expression of $\alpha-\operatorname{IgM}+C p G$ stimulated B cells. (a) Flow cytometry shows the binding to human primary B cells of the two gp120s employed for microarray analysis: R880F $0 \mathrm{M}$ with a high affinity for $\alpha_{4} \beta_{7}$ and 92Th14.12 with a low affinity for $\alpha_{4} \beta_{7}$. (b) Heat map visualization by Partek of gene expression modulation in response to treatment with month- 0 gp120 $(\mathrm{H})$ with a high affinity for $\alpha_{4} \beta_{7}(\mathrm{R} 66 \mathrm{M})$ and a gp120 with a low (L) affinity for $\alpha_{4} \beta_{7}$ (92Th14.12). B cells were treated with the envelopes for $6 \mathrm{~h}$. Statistical significance is reported relative to mock-treated B cells. Categories of the genes modulated by gp $120-a_{4} \beta_{7}$ interaction are specified (DAVID Bioinformatics Tool). (c) FcRL4 mRNA induction at $6 \mathrm{~h}$ in the first set and second set of microarray analysis shown in fold change $(\log 2)$. Data reported are representative of three independent experiments. 

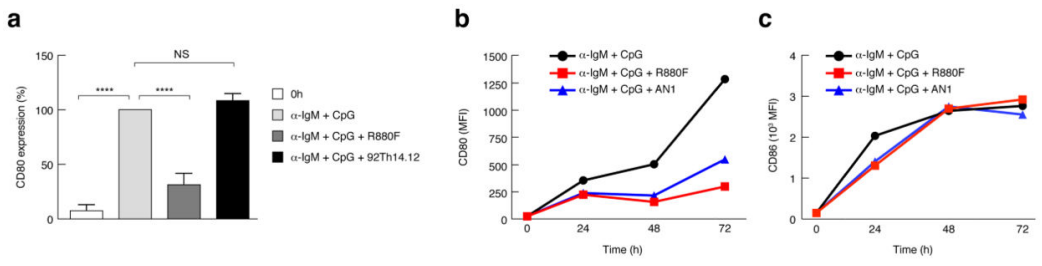

\section{Figure 5.}

CD80 induction by $\alpha-\operatorname{IgM}+\mathrm{CpG}$ stimulation is reduced in presence of an $\alpha_{4} \beta_{7}$-reactive gp120. (a) FACS analysis of CD80 surface expression induced by a-IgM + CpG stimulation for 72h, in the presence or absence of gp120s with high (R880F) versus low (92Th14.12) affinity for $\alpha_{4} \beta_{7}$. Values reported are average $\%$ reactivity normalized to CD80 expression at $72 \mathrm{~h}$ upon B cell stimulation with $\mathrm{a}-\mathrm{IgM}+\mathrm{CpG}$ alone (100\%), $p<0.0001$ (two way ANOVA) (s.e.m bars) (n=3). (b) FACS analysis of CD80 surface expression over time induced by stimulation with a-IgM $+\mathrm{CpG}(24,48,72 \mathrm{~h})$ in the presence or absence of gp120 with high affinity for $\alpha_{4} \beta_{7}$ (R880F) or intermediate affinity for $\alpha_{4} \beta_{7}$ (AN1). (c) FACS analysis of CD86 surface expression on B cells activated by $\mathrm{a}-\mathrm{IgM}+\mathrm{CpG}$ for $24,48,72 \mathrm{~h}$, in presence of gp120s (R880F, AN1, Z185F) with different affinities for $\alpha_{4} \beta_{7}(72 \mathrm{~h})$. Data reported indicate MFI, and are representative of three independent experiments using different donor B cells. 

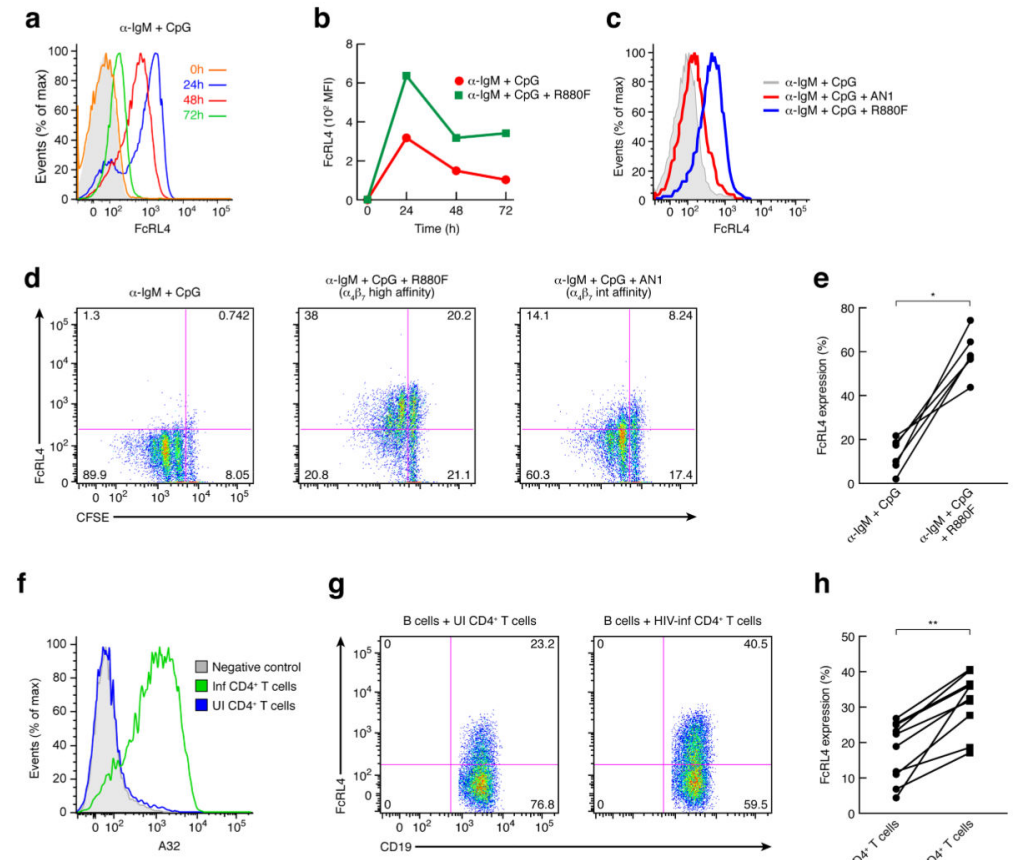

h

Figure 6.

FcRL4 expression induced by a-IgM + CpG stimulation is increased and prolonged in presence of an $\alpha_{4} \beta_{7}$-reactive gp120. (a) FACS analysis of FcRL4 expression over a time course of $0-72 \mathrm{~h}$ on freshly isolated $\mathrm{B}$ cells stimulated with $\mathrm{a}-\mathrm{IgM}+\mathrm{CpG}$. Isotype control in shown as a grey shade. (b) FACS analysis of FcRL4 expression over time (0-72h) on freshly isolated B cells stimulated with $\alpha$ - $\operatorname{IgM}+\mathrm{CpG}+/-$ an $\alpha_{4} \beta_{7}$-reactive gp120. (c) FACS analysis of FcRL4 expression at 72h on freshly isolated B cells stimulated with a-IgM + $\mathrm{CpG}$ in presence or absence of gp120 with a high (R880F) and an intermediate (AN1) affinity for $\alpha_{4} \beta_{7}$. (d) In vitro proliferation assays (CFSE) were performed with B cells that were stimulated with a-IgM + CpG for $96 \mathrm{~h}$ and analyzed by FACS after staining for FcRL4 surface expression. CFSE staining by FcRL4 is presented and is representative of five independent experiments. (e) \% FcRL4 expression on B cells stimulated with a-IgM $+\mathrm{CpG}$ $+/-a_{4} \beta_{7}$-reactive gp120 from 6 independent donors $p=0.03$ (Wilcoxon matched-pairs signed rank test) (n=6). (f) Histogram of a FACS analysis of an A32 (anti-gp120) staining of HIV-1 infected or uninfected CD4+ T cells that were employed in the co-culture experiment. (g) FACS analysis of FcRL4 expression on B cells co-cultured with infected CD4 ${ }^{+} \mathrm{T}^{-}$cells isolated from the same donor. Shown is a representative result from one of ten independent donors of the surface expression of FcRL4 by CD19 detected by FACS after $48 \mathrm{~h}$ of coculture. (h) $\%$ FcRL4 expression on B cells from 10 donors stimulated with a-IgM + CpG and co-cultured with autologous uninfected or HIV-1 infected donor CD4 ${ }^{+} \mathrm{T}$ cells, $p=0.002$ (Wilcoxon matched-pairs signed rank test) $(n=10)$. 
a

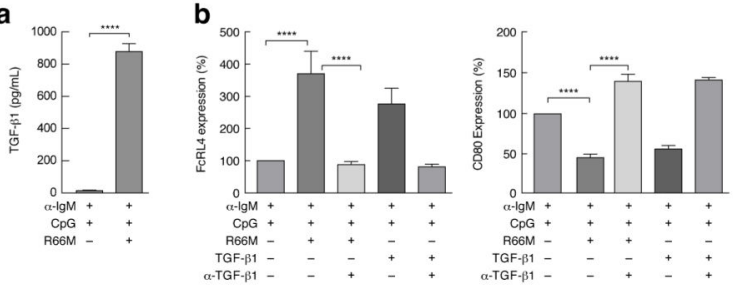

c

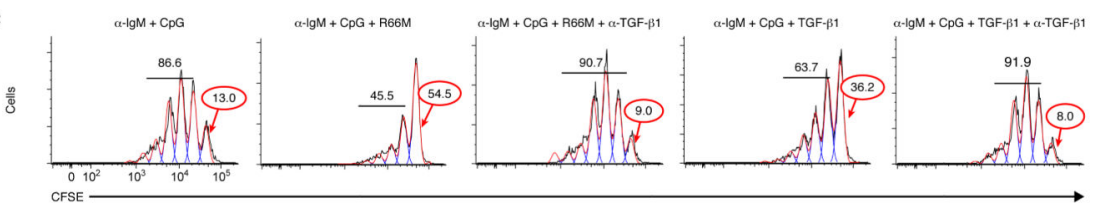

d

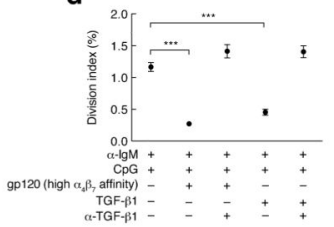

Figure 7.

gp120 induces FcRL4 via the induction of TGF- $\beta 1$. (a) Average TGF- $\beta 1$ ELISA of supernatants from cultured primary B cells from three separate healthy donors stimulated with $\alpha-\operatorname{IgM}+\mathrm{CpG}$ in presence of an $\alpha_{4} \beta_{7}$-reactive gp120 (R66M), $p<0.0001$ (unpaired $t$ test) (s.e.d. bars) (n=3). (b) FACS analysis of \% FcRL4 and \% CD80 expression on a-IgM + CpG stimulated B cells in presence of gp120 or TGF- $\beta 1$. Anti-TGF- $\beta 1$ was employed to block both gp120-mediated and TGF- $\beta 1$-mediated effects. The average \% of cells expressing FcRL4 and CD80, normalized to FcRL4 and CD80 expression at 96h upon B cell stimulation with a-IgM + CpG alone (100\%), $p<0.0001$ (one way ANOVA, Bonferroni Multiple Comparison Test) (s.e.m bars) (FcRL4 n=8) (CD80 n=5). (c) CFSE assay of a-IgM $+\mathrm{CpG}$ induced $\mathrm{B}$ cell proliferation ( $1^{\text {st }}$ panel), in the presence of: an $\alpha_{4} \beta_{7}$-reactive gp120 ( $2^{\text {nd }}$ panel), an $\alpha_{4} \beta_{7}$-reactive gp120 and an anti-TGF- $\beta 1$ ( $3^{\text {rd }}$ panel), soluble TGF- $\beta 1$ ( $4^{\text {th }}$ panel), and soluble TGF- $\beta 1$ and an anti-TGF- $\beta 1$ ( $5^{\text {th }}$ panel) of a representative donor. Cells were cultured for 96h. (d) Division Index (FlowJo) indicating the average number of cell divisions in three independent donors, $p<0.001$ (two-way ANOVA) $(n=3)$. Treatments are listed below the $\mathrm{x}$-axis. 

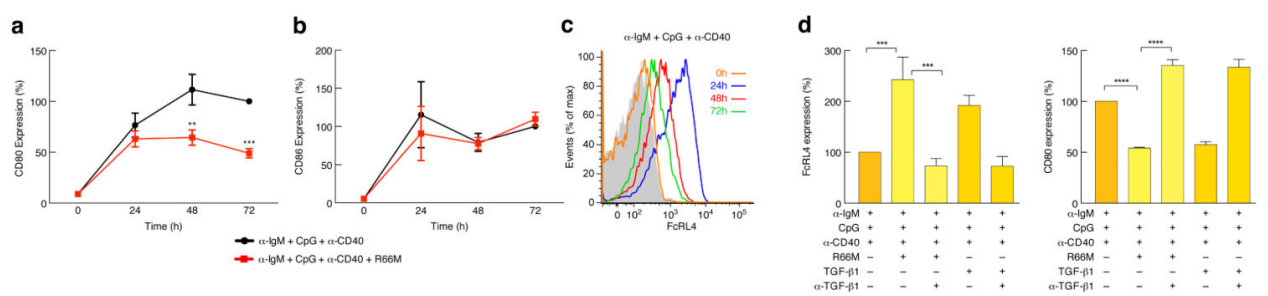

e

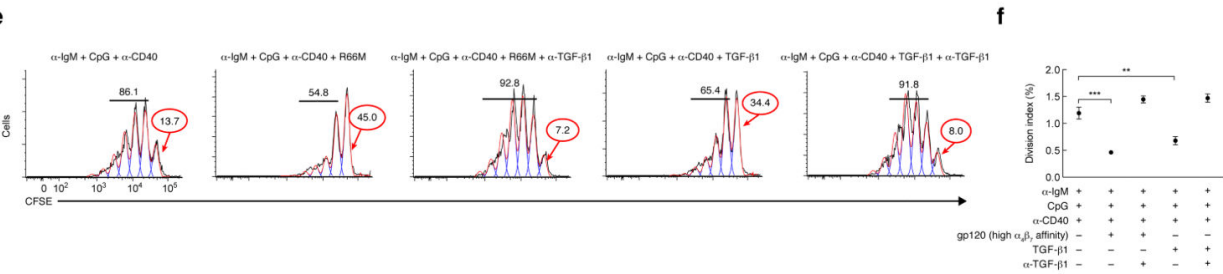

Figure 8.

A T-dependent stimulation of B cells is suppressed by an $\alpha_{4} \beta_{7}$-reactive gp120. (a) FACS analysis over time of the average \% CD80 surface expression in three donors, induced by a$\operatorname{IgM}+\mathrm{CpG}+\mathrm{a}-\mathrm{CD} 40$ stimulation $(24,48,72 \mathrm{~h})$ in presence or absence of an $\mathrm{a}_{4} \beta_{7}$-reactive gp120. Values reported are average \% reactivity normalized to CD80 expression at $72 \mathrm{~h}$ upon B cell stimulation with $\mathrm{a}-\mathrm{IgM}+\mathrm{CpG}+\mathrm{a}-\mathrm{CD} 40$ alone $(100 \%), p<0.001$ at $72 \mathrm{~h}$ (two way ANOVA) (s.e.m bars) (n=4). (b) FACS analysis over time of the average \% CD86 surface expression in three donors, induced by a-IgM + CpG + aCD40 stimulation (24, 48, $72 \mathrm{~h}$ ) in presence or absence of an $\alpha_{4} \beta_{7}$-reactive gp120. Values reported are average $\%$ reactivity normalized to $\mathrm{CD} 86$ expression at $72 \mathrm{~h}$ upon $\mathrm{B}$ cell stimulation with $\mathrm{a}-\mathrm{IgM}+\mathrm{CpG}$ + a-CD40 alone (100\%) (two way ANOVA) (s.e.m bars) $(n=4)$. (c) FACS analysis for FcRL4 expression over a time course of $0-72 \mathrm{~h}$ on freshly isolated B cells stimulated with aIgM $+\mathrm{CpG}+\mathrm{a}-\mathrm{CD} 40$. Isotype control in shown as a grey shade. (d) FACS analysis of the average \% FcRL4 and \% CD80 expression induced on a-IgM + CpG + a-CD40 stimulated B cells in presence of R66M or TGF- $\beta 1$. Anti-TGF- $\beta 1$ was employed to block both gp120mediated and TGF- $\beta 1$-mediated effects. The average \% of cells expressing FcRL4 and CD80 is reported normalized to FcRL4 and CD80 expression at 96h upon B cell stimulation with $a-\operatorname{IgM}+\mathrm{CpG}+\mathrm{a}-\mathrm{CD} 40(100 \%), p<0.001$ and $p<0.0001$ (one way ANOVA, Bonferroni Multiple Comparison Test) (s.e.m bars) (FcRL4 n=4) (CD80 n=5). Values are normalized to \% FcRL4 expression on a-IgM + CpG + a-CD40 stimulated B cells (100\%). (e) CFSE assay of a-IgM $+\mathrm{CpG}+\mathrm{aCD} 40$ induced $\mathrm{B}$ cell proliferation ( $1^{\text {st }}$ panel), in the presence of: an $\alpha_{4} \beta_{7}$-reactive gp120 ( $2^{\text {nd }}$ panel), an $\alpha_{4} \beta_{7}$-reactive gp120 and an anti-TGF- $\beta 1$ ( $3^{\text {rd }}$ panel), soluble TGF- $\beta 1$ ( $4^{\text {th }}$ panel), and soluble TGF- $\beta 1$ and an anti-TGF- $\beta 1$ ( $5^{\text {th }}$ panel) of a representative donor. Cells were cultured for 96h. (f) Division Index (FlowJo) indicating the average number of cell divisions in three independent donors, $p<0.001$ (twoway ANOVA) $(n=3)$. Treatments are listed below the $x$-axis. 


\section{Table 1}

Genes upregulated by gp120- $\alpha_{4} \beta_{7}$ interaction

\begin{tabular}{ll} 
Biological process & Genes present \\
\hline Regulation of apoptosis & $A B R, A C V R 1, A D A, B A R D 1, B C L 6, B I R C 2, C 14 O R F 153, C A S P 8 A P 2, C C L 2, C D 27, C D 38$, \\
& $C D K N 1 A(p 21), C D K N 2 A, D Y R K 2, F U R I N, I D 3, I D O 1, I E R 3, I L 1 A, I L 1 B, I L 2 R A, I N H B A$, \\
& $J U N, K L F 10, K R A S, M Y O 18 A, N O T C H 1, P P P 1 R 13 B, P R K C I, P T G S 2, R R M 2 B, R X R A$, \\
& $S E M A 4 D, S E R P I N B 2, S M A D 6, S M A D 7, S P H K 1, S T K 17 A, T G F B 1, T N F, T N F A I P 8, T N F R S F 9$ \\
Chemotaxis & $C C L 2, C C L 20, C C L 4 L 1, C C R 6, C C R L 2, C X C L 16, E N G, I L 1 B, I L 8, N R P 2, P L A U R$ \\
Immune/Inflammatory response & $A C V R 1, C C L 2, C C L 20, C C L 4 L 1, F C R L 4, I D O 1, I L 1 A, I L 1 B, I L 1 R N, I L 2 R A, I R A K 2, T N F A I P 6$, \\
& $K D M 6 B, R G S 1, R X R A, T G F B 1, T L R 1, T N F$ \\
Defense response & $A C V R 1, A N K R D 1, C C L 2, C C L 20, C C L 4 L 1, C C R 6, C D 83, C X C L 16, H I S T 1 H 2 B E, I D O 1, I L 1 A$, \\
& $I L 1 B, I L 1 R N, I L 2 R A, I N H B A, I R A K 2, K D M 6 B, L S P 1, R X R A, T G F B 1, T L R 1, T N F$ \\
Positive regulation of lymphocyte & $A D A, B C L 6, B L M, C D K N 1 A(p 21), C D 38, I L 1 B, I L 2 R A, R G S 1$ \\
proliferation & \\
\hline
\end{tabular}

Genes down-modulated by gp120- $\alpha_{4} \beta_{7}$ interaction

\begin{tabular}{|c|c|}
\hline Biological process & Genes present \\
\hline Immune response & $\begin{array}{l}\text { BMP6, BTLA, CBLB, CD86, CR1, HLA-DOB, IGKC, IGKV1-5, IGKV4-1, LILRB1, LY9, } \\
\text { NCR3, OAS1, SKAP1 }\end{array}$ \\
\hline Inflammatory response & ALOX5, BMP6, CR1, CYSLTR1, NCR3, PLA2G7 \\
\hline Defense response & ALOX5, BMP6, CR1, CYSLTR1, FGR, HCK, NCR3, PLA2G7, RNASE6 \\
\hline Positive regulation of immune system process & $C B L B, C D 86, C R 1, N C K 2, S H 2 B 2, F C E R 2, N C R 3, S K A P 1$ \\
\hline
\end{tabular}




\section{Table 2}

Genes upregulated by gp120-- $\alpha_{4} \beta_{7}$ interaction

\begin{tabular}{ll} 
Biological process & Genes present \\
\hline Leukocyte activation and differentiation & $A D A, B C L 3, C D 79 A, C S F 2, C X C R 4, E L F 4, I L 10, L C P 2, M Y H 9, T G F B 1, T L R 1, T L R 6$ \\
Regulation of apoptosis & $A B R, A D A, B C L 3$, BTG2, CDKN1 (P21),CSF2, CTSB, FOXL2, FURIN, ID3, IL10, IL2RB, IL6R, \\
& INPP5D, KLF10, PTGS2, RUNX3, SMAD7, SPHK1, TGFB1, TNFRSF9 \\
Leukocyte proliferation & $C D 79 A, C X C R 4, E L F 4, I L 10, T G F B 1$ \\
Regulation of lymphocyte proliferation & $A D A, C D K N 1 A(P 21), F C R L 4, I L 10, I N P P 5 D, T G F B 1, T N F R S F 14$ \\
Immune system development & $A D A, B C L 3, C D 79 A, C S F 2$, DNASE2, ID2, IL10, MYH9, TGFB1, TIPARP, TTC7A \\
\hline
\end{tabular}

Genes down-modulated by gp120-- $\alpha_{4} \beta_{7}$ interaction

\begin{tabular}{ll} 
Biological process & Genes present \\
\hline Immune response & $B N I P 3, C D 86$, ENPP2, GBP1, IFI44L, IFI6, LILRB1, LOC652493, LY9, NCF2, OAS1, OAS3, PTPRC, TRIM22 \\
Cell proliferation & $C D 86, I L 15 R A, L A M P 3$, PTPRC, STAT4, TCF7L2 \\
\hline
\end{tabular}

